\title{
THE IN VITRO EFFECT OF FLUORIDATED MILK IN A BACTERIAL BIOFILM - ENAMEL MODEL
}

\author{
Wolfgang H. Arnold ${ }^{\mathrm{a}}$, Stefan Forer ${ }^{\mathrm{a}}$, Joerg Heesen ${ }^{\mathrm{a}}$, Keren Yudovich ${ }^{\mathrm{b}}$, Doron Steinberg ${ }^{\mathrm{b}}$, \\ Peter Gaengler ${ }^{\mathrm{c}}$
}

\author{
a Department of Anatomy, Faculty of Dental Medicine, University of Witten/Herdecke, Germany \\ ${ }^{b}$ Institute of Dental Sciences, Faculty of Dental Medicine, Hebrew University-Hadassah, Jerusalem, Israel \\ c Department of Conservative Dentistry, Faculty of Dental Medicine, University of Witten/Herdecke, Germany \\ e-mail:wolfa@uni-wh.de
}

Received: March 20, 2006; Accepted: April 10, 2006

Key words: Biofilm/Milk/Fluoride/Dental caries

\begin{abstract}
Objectives: The purpose of this study was to investigate the effect of milk and fluoridated milk on bacterially induced caries-like lesions. Sample and methods: Extracted impacted human molars were cut in half and covered with a varnish leaving a $4 \times 4 \mathrm{~mm}$ window. The samples were coated with biofilm of $S$. sobrinus and were further divided into three experimental groups of $S$. sobrinus, $S$. sobrinus and milk and $S$. sobrinus and fluoridated milk. As negative controls served teeth incubated in saline. Of twenty tooth halves serial ground sections were cut through the lesions and investigated with polarization light microscopy (PLM) and scanning electron microscopy (SEM) and EDX element analysis. The PLM photographs were used for 3D reconstruction, volumetric assessment and determination of the extension of the lesion zones. Of eight tooth halves the biofilm on the enamel surface was studied with SEM and EDX element analysis. Results: Volumetric assessment showed a statistically significant difference in the volume of the body of the lesion and the translucent zone between the milk group and fluoridated milk group. Quantitative element analysis demonstrated significant differences between sound enamel and the superficial layer in the fluoridated milk group. The biofilm on the enamel surface showed an increased Ca content in the milk group and fluoridated milk group. Conclusions: Milk as a common nutrient seems to play a complex role in in-vitro biofilm - enamel interactions stimulating bacterial demineralization on one hand, and, as effective fluoride carrier, inhibits caries-like demineralization.
\end{abstract}

\section{INTRODUCTION}

The effect of fluoridated milk on inhibition and remineralizing treatment of initial caries lesions has been studied in clinical ${ }^{1-4}$ and experimental in vitro investigations ${ }^{5-8}$. In experimental studies so far a chemical demineralization model has been used ${ }^{5-9}$ which does not take into account the oral bacterial environment. Therefore, in this study a bacterial demineralization model was used which mimics more closely the oral conditions to study the effect of fluoridated milk on enamel demineralization and remineralization.

Oral bacteria are the main constituents of the dental biofilm plaque which covers the tooth surface ${ }^{10,11}$ and, therefore enamel demineralization is caused by the production of organic acids from bacterial metabolism ${ }^{12,13}$ Several factors determine caries development; acid production, plaque adherence onto the enamel surface and bacterial metabolism which is influenced by the dietary regime of the host ${ }^{14}$ Caries activity of dental plaque is dependent on the degree of calcium saturation within the plaque which influences demineralization of the enamel surface. ${ }^{15}$

The anticariogenic effect of fluoride is well established ${ }^{16}$ and widely accepted. However, there is still debate about the mechanism of fluoride in enamel remineralization. Enamel remineralization is not only dependent on bio-availability of fluoride but also on the calcium and phosphorus content in the oral cavity. Milk contains relatively high concentrations of calcium and phosphorus and may therefore be an ideal carrier for remineralization of ename ${ }^{16,17}$ It has been debated whether milk alone and milk products have a cariostatic effect ${ }^{18-21}$ Recent investigations have shown that fluoridated milk is more effective in caries inhibition than milk alone $e^{5,6,8,9}$ Dietary regimes and fluoride bioavailability are therefore the keystone for caries inhibition and remineralization.

It was therefore the aim of this study to investigate the influence of fluoridated milk on enamel demineralization and remineralization in an experimental bacterial biofilm model to achieve further knowledge about fluoridated nutritional components on caries prevention.

\section{MATERIAL AND METHODS}

Extracted, impacted human third molars were used for the experiments. The samples were stored in $0.9 \% \mathrm{NaCl}$ solution containing $0.1 \%$ Thymol until further use. The crowns were cut from the root and were further divided 
into two halves in mesio-distal direction along the central fossa. The samples were washed thoroughly and sterilized by autoclave, after which the samples were coated with a varnish leaving a $4 \times 4 \mathrm{~mm}$ window on the smooth surface. Five control tooth halves were incubated with saline. The rest of the samples were incubated for 48 hours with S. sobrinus in the presence of $4 \%$ sucrose in order to form a biofilm on the samples. The samples where divided into three experimental groups: 1) five tooth samples incubated with bacterial suspension of $S$. sobrinus (group BS), 2) seven tooth samples incubated with bacterial suspension and whole milk ( $1 \%$ fat; group BSM), 3) seven tooth samples incubated with bacterial suspension and fluoridated milk ( $110 \mathrm{mg} \mathrm{NaF} / 1=50$ ppm F; group BSFM). The incubation media were changed every two days and once every two weeks a new inoculum of bacteria supplemented with $4 \%$ sucrose was added. The total incubation period lasted for six months, during that course the bacterial purity of the samples was checked routinely.

Thirteen tooth samples were used for serial sectioning, polarization light microscopy and quantitative element analysis using the SEM EDX system of which 10 were experimental sites and 3 were controls. Two tooth samples of each group were used for studying the $\mathrm{Ca}, \mathrm{P}$ and $\mathrm{F}$ content of the experimental dental biofilm (EDB).

\section{POLARIZATION LIGHT MICROSCOPY}

Three samples of the BS group and five samples of the BSM and BSFM group were embedded in Technovit 9100 (Kulzer) together with four perpendicular oriented metal positioners as fiducial markers for correct superimposition of the consecutive serial ground sections of $80 \mu \mathrm{m}$ thickness. A loss of $200 \mu \mathrm{m}$ between each section was due to the thickness of the sawing blade (Leica 1600). Between 15 and 20 serial sections were obtained from one sample of which 5 to 8 sections demonstrated the experimental caries-like lesion. The serial sections were then investigated by polarization light microscopy. Digital microphotographs of each section exhibiting caries-like lesions were taken.

\section{D RECONSTRUCTION}

From these microphotographs 3D-reconstructions of the different zones of the lesions were constructed using Auto-CAD 14 computer program. The outlines of enamel and of lesion profiles and zones were traced on the computer screen consecutively and digitized. The distance between every section was $280 \mu \mathrm{m}(80 \mu \mathrm{m}$ thickness of the section and $200 \mu \mathrm{m}$ loss). From the digitized outlines the total volumes and the extension of the superficial layer, the body of the lesion and the translucent zone into sound enamel were calculated and compared using descriptive statistics.

\section{SCANNING ELECTRON MICROSCOPY}

For studying the EDB three samples of each group were fixed in $2.5 \%$ glutaraldehyde after incubation. One half of the EDB was removed after fixation, then the samples were critical point dried, covered with carbon and used for element determination with EDX analysis of the biofilm, and underneath the biofilm on the enamel surface.

From serial sections of the other thirteen samples three sections of each tooth showing the lesion were coated with carbon and examined with a scanning electron microscope (Philips XL 30 FEG) at $20 \mathrm{kV}$ using backscattered electron detector. Element content in weight \% of $\mathrm{Ca}, \mathrm{P}, \mathrm{C}$ and $\mathrm{F}$ was measured with energy dispersive X-ray analysis (EDX) by means of S-UTW (EDAX) detector. The count rate was between 1800 and 2000 counts per second with a dead time of $30 \%$. Measuring time was $30 \mathrm{~s}$ (live seconds) with a resolution of $135.8 \mathrm{eV}$ and an amplification time of $50 \mu \mathrm{s}$. In each of the different zones 3 spot measurements (spot size $2 \mathrm{~nm}$ ) were carried out in every section.

\section{STATISTICS}

The measured values were statistically evaluated using the non-parametric Kruskal-Wallis-test and the ANOVA test for repeated measurements. All calculations were carried out with SPSS 10.0 for Windows computer program. As three statistical tests were carried out with the same set of data the Bonferoni correction for $\alpha=0.05$ resulted in a p-value of 0.016 .

\section{RESULTS}

Polarization light microscopy revealed distinct homogenous caries-like lesions in all groups. The superficial layer of the samples incubated in bacterial suspension and fluoridated milk (group BSFM) was the largest (Fig. 1). Volumetric assessment of the body of the lesion showed values between $610 \mu \mathrm{m}^{3}$ and $810 \mu \mathrm{m}^{3}$ for the samples incubated with bacterial suspension (group BS), 290-810 $\mu^{3}$ for group BSFM, and $1400-4300 \mu \mathrm{m}^{3}$ for group BSM. The volume of the body of the lesion in group BSM was about 5 fold larger than in both other groups (Table 1). The volumes of the translucent zone in group BS were in a range between 260 and $1570 \mu^{3}$, for group BSFM between $360-1130 \mu \mathrm{m}^{3}$ and for group BSM between $120-340 \mu \mathrm{m}^{3}$ (Table 1).

$\mathrm{Ca}, \mathrm{P}$ and $\mathrm{C}$ content varied considerably between the superficial layer and sound enamel. A statistically significant difference in the $\mathrm{Ca}$ and $\mathrm{P}$ content was found between the superficial layer and sound enamel in group BSFM and BS (Figs. 2 and 3). The C content in the superficial layer was $37.37 \mathrm{wt} \%( \pm 28.98)$ in the BS group, $12.84 \mathrm{wt} \%( \pm 6.61)$ in the BSM group and $41.75 \mathrm{wt} \%$ $( \pm 34.01)$ in the BSFM group. All values were significantly 
Table 1. Volumes and extension of the lesion zones in the different groups.

\begin{tabular}{|c|c|c|c|c|}
\hline Sample group & $\begin{array}{c}\text { Volume of the Body } \\
\text { of the Lesion }\end{array}$ & $\begin{array}{c}\text { Volume of } \\
\text { Translucent Zone }\end{array}$ & $\begin{array}{c}\text { Extension of the } \\
\text { Body of the Lesion }\end{array}$ & $\begin{array}{c}\text { Extension of } \\
\text { Translucent Zone }\end{array}$ \\
\hline BS & 810 & 1570 & 290 & 330 \\
\hline BS & 610 & 380 & 310 & 410 \\
\hline BS & 730 & 260 & 280 & 270 \\
\hline BSFM & 290 & 1130 & 290 & 270 \\
\hline BSFM & 810 & 430 & 760 & 270 \\
\hline BSFM & 530 & 540 & 430 & 260 \\
\hline BSFM & 610 & 460 & 590 & 290 \\
\hline BSFM & 380 & 360 & 310 & 260 \\
\hline BSM & 1400 & 120 & 300 & 280 \\
\hline BSM & 3700 & 260 & 310 & 290 \\
\hline BSM & 4300 & 210 & 240 & 260 \\
\hline BSM & 3600 & 340 & 290 & 270 \\
\hline BSM & 4100 & 230 & 270 & 310 \\
\hline
\end{tabular}

Volumes are expressed in $\mu \mathrm{m}^{3}$, extensions are expressed in $\mu \mathrm{m}$.

Table 2. Mean values, standard deviation and statistical comparison of the $\mathrm{Ca} / \mathrm{P}$ ratio in the superficial layer.

\begin{tabular}{|c|c|c|c|}
\cline { 2 - 4 } \multicolumn{1}{c|}{} & Sound enamel & Bacteria + whole milk & Bacteria + F-milk \\
\hline Mean & 1.98 & 1.99 & 1.90 \\
\hline SD & 0.13 & 0.15 & 0.54 \\
\hline Statistical comparison & $\longleftarrow$ & $\mathrm{p}<0.001$ & $\uparrow$ \\
\hline
\end{tabular}

There is a statistically significant difference of the $\mathrm{Ca} / \mathrm{P}$ ratio between sound enamel and the bacteria + F-milk group.

Table 3. Mean values of the element content in wt\% of Ca, $\mathrm{P}$ and $\mathrm{F}$ of the biofilm and enamel surface underneath the biofilm.

\begin{tabular}{|c|c|c|c|c|c|c|}
\hline \multirow{2}{*}{ Sample group } & \multicolumn{3}{|c|}{ Biofilm } & \multicolumn{3}{c|}{ Cleaned surface } \\
\cline { 2 - 7 } & $\mathrm{Ca}$ & $\mathrm{P}$ & $\mathrm{F}$ & $\mathrm{Ca}$ & $\mathrm{P}$ & $\mathrm{F}$ \\
\hline BS & 0.63 & 0.42 & 0.2 & 38.9 & 19.3 & 0.6 \\
\hline BSM & 1.2 & 0.57 & 0.1 & 35.7 & 20.8 & 0.8 \\
\hline BSFM & 1.5 & 0.7 & 0.2 & 35.8 & 21.8 & 1.2 \\
\hline
\end{tabular}

An increased amount of $\mathrm{Ca}$ and $\mathrm{P}$ was found in the biofilm of the milk and fluoridated milk group. 


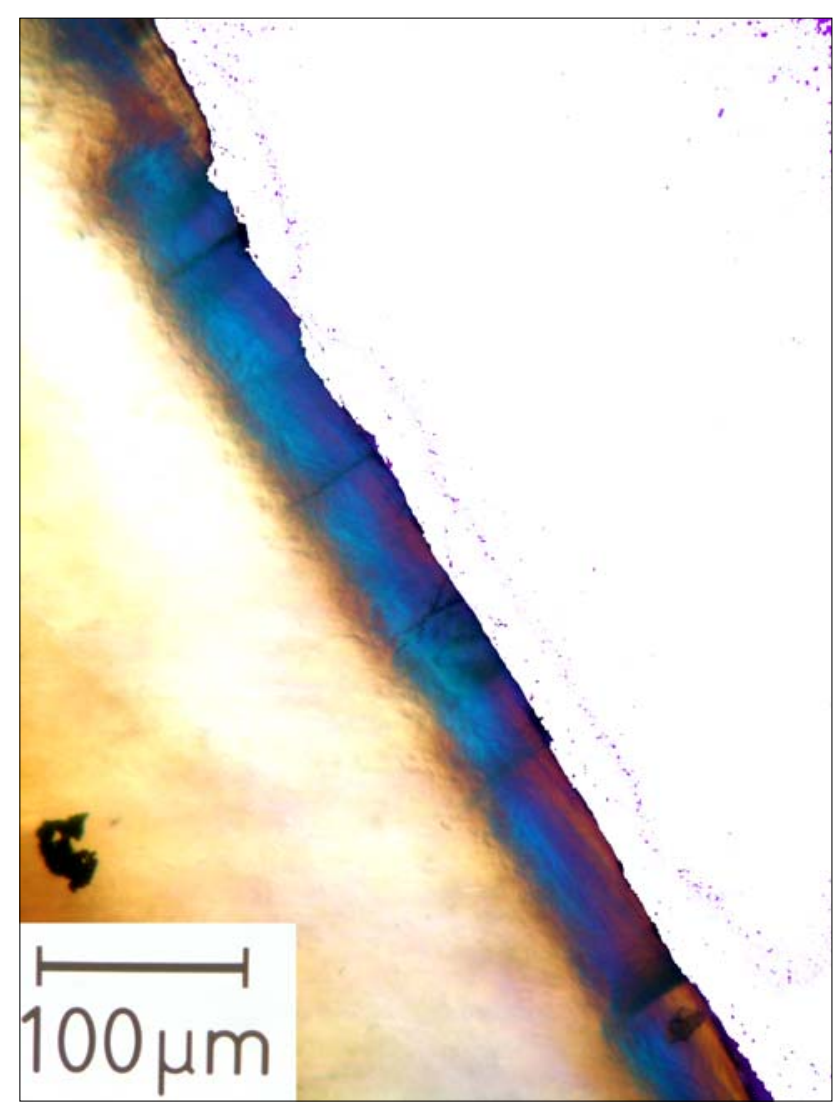

a

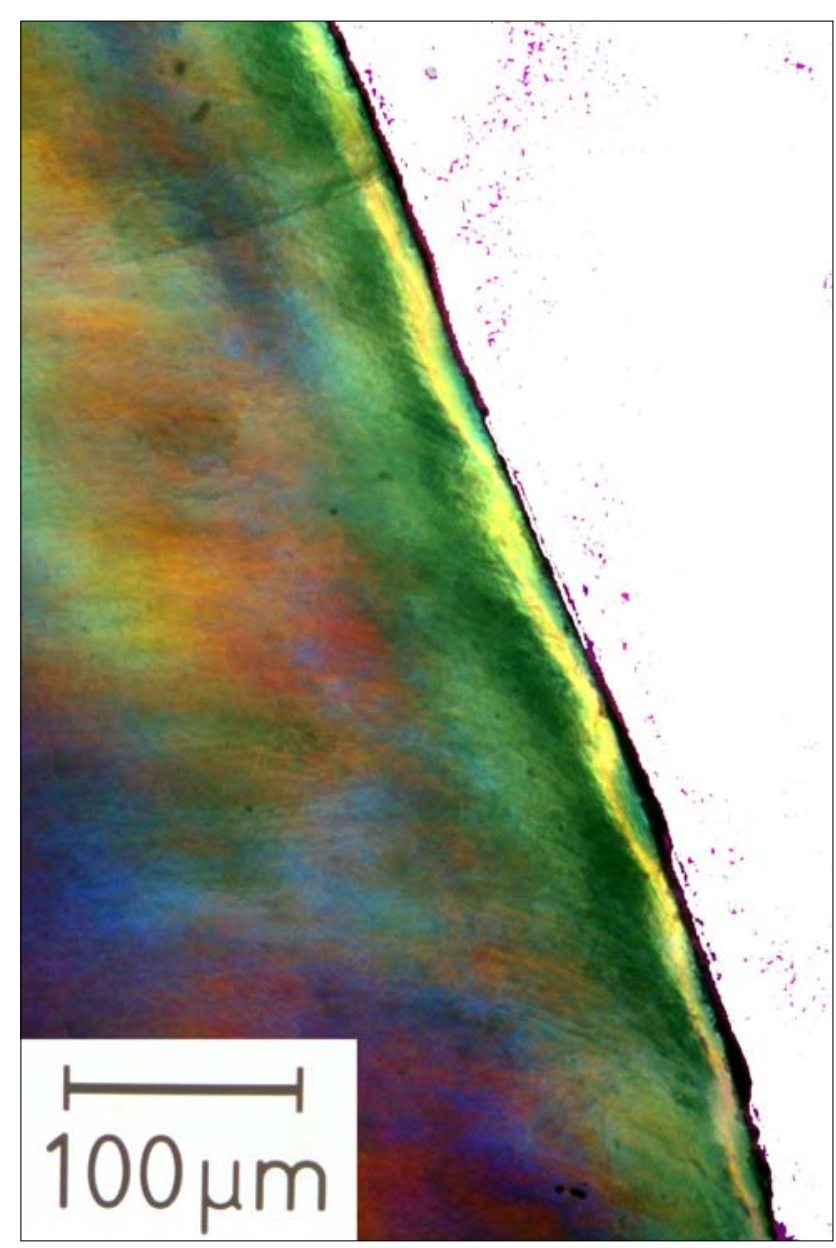

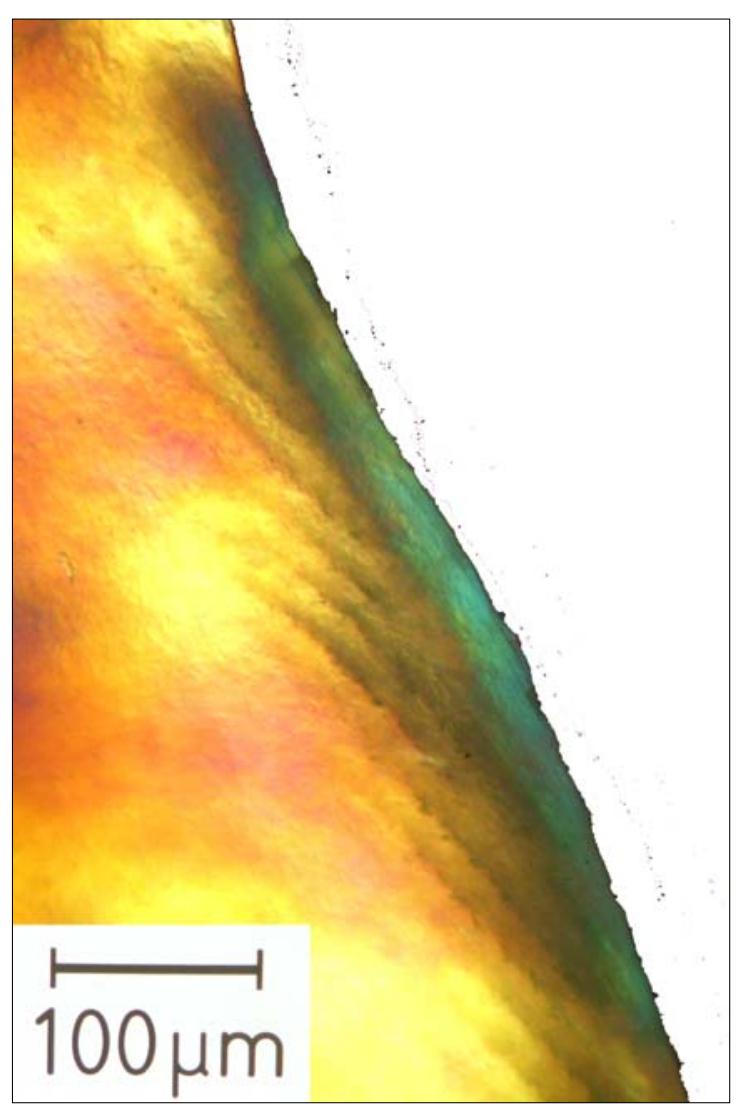

b

Fig. 1. Polarization light micrograph of experimental caries-like lesions. a) = incubation with bacterial suspension (group BS), b) = incubation with whole milk (group BSM), c) = incubation with fluoridated milk (group BSFM). The lesion with fluoridated milk showes an increased extension of the superficial layer. 


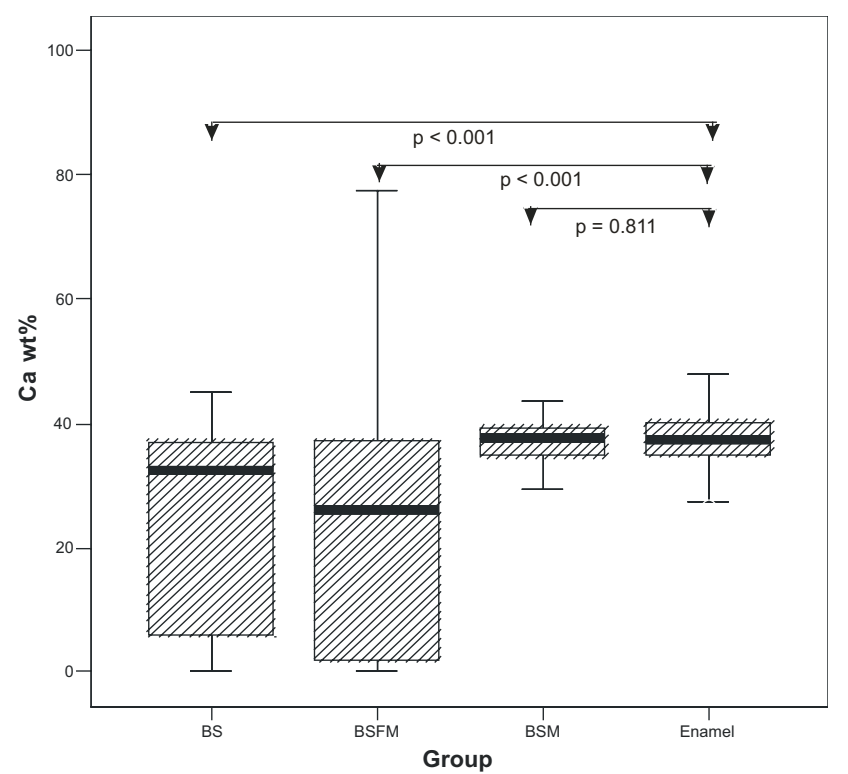

Fig. 2. Ca content in the superficial layer. Group BS = incubation with bacterial suspension, group BSFM = incubation with bacteria and fluoridated milk, group BSM = incubation with milk. Ca content on the Bs and BSFM group is significantly lower than in sound enamel.

larger compared to sound enamel ( $10.68 \mathrm{wt} \% \pm 4.59)$ with a relatively large variance between groups BS and BSFM (Fig. 4). Ca/P ratio in the surface layer was $1.91( \pm 0.27)$ in the BS group, $1.99( \pm 0.15)$ in the BSM group and 1.90 $( \pm 0.54)$ in the BSFM group. Compared to sound enamel $(1.98 \pm 0.13)$ the $\mathrm{Ca} / \mathrm{P}$ ratio was statistically significant different in the BSFM group (Table 2). The Ca content in the body of the lesion after incubation with bacterial suspension (group BS) was $35.99 \mathrm{wt} \%( \pm 4.38)$, in the BSM group $39.21 \mathrm{wt} \%( \pm 4.23)$ and in the BSFM group 35.69 wt $\%( \pm 6.98)$ with a significant difference between the BSM group and sound enamel. The P content in the body of the lesion was $18.22 \mathrm{wt} \%( \pm 1.86)$ in the BS group, $19.63 \mathrm{wt} \%( \pm 1.7)$ in group BSM and $17.96 \mathrm{wt} \%( \pm 3.17)$ in group BSFM. The F content in the superficial layer of group BS was $0.44 \mathrm{wt} \%( \pm 0.36)$ in group BSFM $0.39 \mathrm{wt} \%$ $( \pm 0.22)$ and that of group BSM was $0.33 \mathrm{wt} \%( \pm 0.2)$. $\mathrm{F}$ content did not differ statistically in any group or any lesion zone.

Measurements of the element content for $\mathrm{Ca}, \mathrm{P}$ and $\mathrm{F}$ showed no differences on the enamel surface underneath the biofilm (Table 3). The Ca content within the biofilm was higher in group BSFM and BSM (1.2 and 1.5 wt\%) than in group BS $(0.61 \mathrm{wt} \%)$. The Fluor content was similar in all three groups (Table 3 ).

\section{DISCUSSION}

Dental caries is the result of enamel demineralization caused by acid produced by bacteria in dental biofilms. It is well established that fluoride reduces the develop-

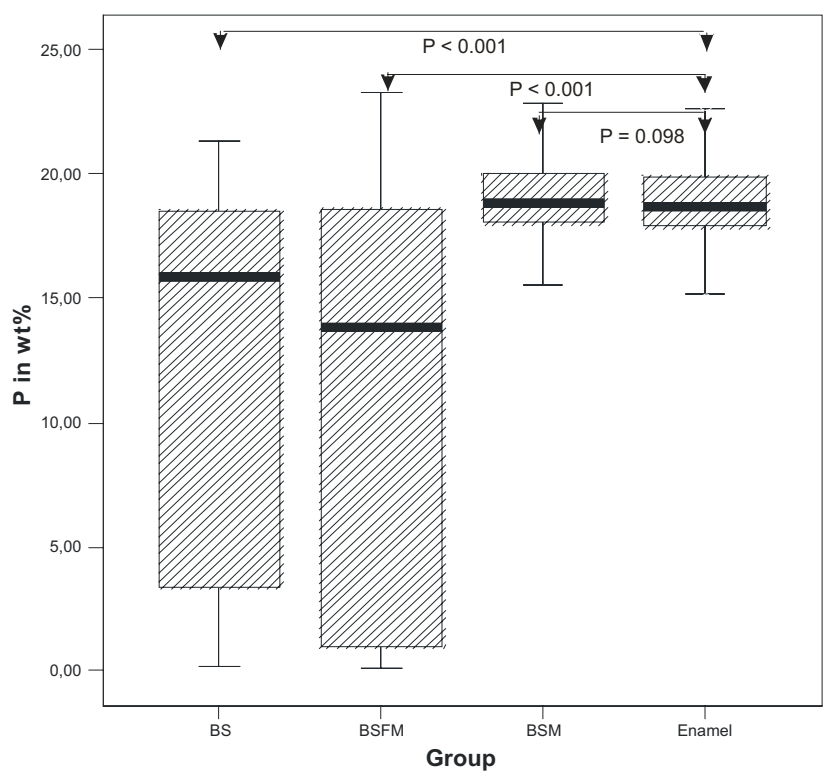

Fig. 3. $P$ content in the superficial layer. Group BS = incubation with bacterial suspension, group BSFM = incubation with bacteria and fluoridated milk, group BSM = incubation with milk. $\mathrm{P}$ content on the Bs and BSFM group is significantly lower than in sound enamel.

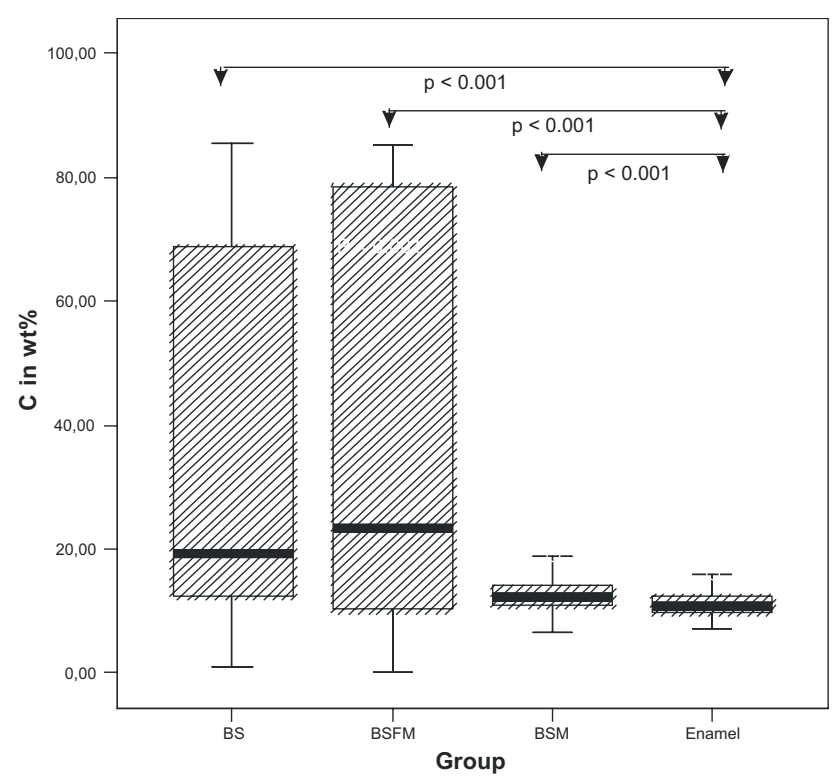

Fig. 4. $\mathrm{C}$ content in the superficial layer. $\mathrm{BS}=$ incubation with bacterial suspension, group BSFM = incubation with bacteria and fluoridated milk, group $\mathrm{BSM}=$ incubation with milk. $\mathrm{P}$ content on the Bs and BSFM group is significantly lower than in sound enamel. The largest $\mathrm{C}$ content was found in the BSFM group. 
ment of caries lesions. A considerable amount of research has been conducted on investigating the influence of various foods on caries development ${ }^{22-24}$ It has also been discussed, that milk and milk products may have a cariostatic effect ${ }^{19,20,25}$ The cariostatic effect of milk and milk products may be due to their high content of $\mathrm{Ca}$ and $\mathrm{P}$ ions, the buffer capacity, or to the content of casein phosphopeptides ${ }^{17,20,26}$. However, there has been a controversial discussion about the fluoride availability in milk $^{27}$. Milk fluoridation has been suggested as an alternative to water fluoridation because milk is an important food for children ${ }^{1,2,4,5}$.

Previous studies have shown that milk and fluoridated milk reduces the caries progression in enamel ${ }^{6,8,9}$ and on root surfaces ${ }^{7}$. It has been discussed that this effect may be due either to incorporation of fluoride into the enamel surface which may result in the formation of fluor-apatite ${ }^{9}$ or to an increase in remineralization of enamel apatite ${ }^{6}$. The present study using a biofilm model showed decreased $\mathrm{Ca}$ content in the superficial layer of the bacteria and fluoridated milk group, but not in the bacteria and milk group. The $\mathrm{Ca} / \mathrm{P}$ ratio, however, resembled that of the $\mathrm{Ca} / \mathrm{P}$ ratio of sound enamel reflecting a normal hydroxyapatite composition. Furthermore the $\mathrm{Ca}$ and $\mathrm{P}$ content in the superficial layer of the BSM group was similar to that of sound enamel. The porous volume of the superficial layer of the BSFM group is obviously larger than in the other groups with little remineralization enabling diffusion of $\mathrm{Ca}$ and $\mathrm{P}$ ions into deeper parts of the lesion and re-precipitation of hydroxyapatite in the presence of fluoride ions. This assumption is supported by the measurements of the $\mathrm{C}$ content as this reflects the porosity of enamel due to imbibition of embedding resign and which was similar to that of sound enamel in the BSM group. As the body of the lesion in the BSM group is larger than in the BS and BSFM group the higher $\mathrm{Ca}$ content in the surface layer of the BS group may be due to reprecipitation of $\mathrm{Ca}$ and $\mathrm{P}$ from dissolved hydoxyapatite of the body of the lesion.

The results showed the smallest body of the lesion after incubation with fluoridated milk. The higher porosity of the superficial layer in the BSFM group may have resulted in a higher remineralization of the body of the lesion due to better diffusion of $\mathrm{Ca}$ and $\mathrm{P}$ ions.. The larger translucent zone in the bacteria + fluoridated milk group may be explained by the re-precipitation of $\mathrm{Ca}$ and $\mathrm{P}$ in the advancing front of the carious lesion. In this case mainly diffusion of dissolved ions takes place between the body of the lesion and the translucent zone but there is less diffusion between the body of the lesion and the superficial layer.

In laboratory models the development of experimental plaque and its influence on enamel demineralization is strongly dependent on nutritional and environmental conditions $^{11,13}$. The small body of the lesion in the BS group can be explained by the lack of other nutritional components in the incubation medium reducing bacterial metabolism. Thus in the BSM group the body of the lesion is relatively large due to accelerated bacterial metabolism supported by the nutritive effect of milk.
It has been shown that the $S$. mutans enolase is inhibited by fluoride and therefore reduces bacterial metabolism ${ }^{28}$. Fluoridated milk therefore, may increase remineralization and/or inhibit bacterial metabolism and reduce demineralization. A previous in vitro studiy showed that milk alone does not reduce demineralization compared to pure demineralization solution in a chemical demineralization model because no differences in the volume and the mineral content were found between whole milk and demineralization solution ${ }^{6}$. In this bacterial model whole milk alone may accelerate bacterial metabolism thus contributing to demineralization. Bacteria alone, without additional alimentary factors, lead to less demineralization and a smaller body of the lesion similar to that of fluoridated milk.

In this biofilm model the milk contained 50 ppm fluoride. It has been reported that small amounts of fluoride inhibit enamel demineralization ${ }^{29,30}$. Higher concentrations of fluoride may also have an inhibitory effect on bacterial acid production ${ }^{31}$ hence inhibiting enamel demineralization. Therefore the caries lesions in the bacterial model are smaller and less pronounced. It could also be shown that neither in the biofilm nor in the enamel surface underneath the biofilm there is an increased amount of F measurable. It is therefore likely that F is not incorporated into the biofilm of superficial dental enamel.

In this study it could be shown that whole milk with $1 \%$ fat added to an experimental biofilm model of $S$. sobrinus over a time period of six months contributes to enamel demineralization resulting in a three to ten fold larger body of the lesion. Obviously, whole milk accelerates bacterial metabolism and biofilm formation and maturation $^{26}$. Fluoridated milk may act two fold either increasing enamel remineralization or inhibiting bacterial metabolism within the dental biofilm ${ }^{28}$.

It is concluded that, within the limits of two experimental in-vitro models of enamel demineralization under chemical conditions ${ }^{6}$ and due to medium term biofilm maturation, milk plays a very complex role. Exposure of enamel to milk results in the inhibition of demineralization over a period of six months on one hand, on the other hand milk itself contributes to biofilm maturation resulting in a much higher demineralization potential and greater volume of lesions. According to the results of both models there is no doubt that milk is an effective fluoride carrier thus preventing lesion progression, but unable to prevent the initiation of the demineralizng process.

\section{REFERENCES}

1. Banoczy J, Zimmermann P, Pinter A, Hadas E, Bruszt V: (1983) Effect of fluoridated milk on caries: 3-year results. Community Dent Oral Epidemiol 11, 81-85.

2. Banoczy J, Zimmermann P, Hadas E, Pinter A, Bruszt V: (1985) Effect of fluoridated milk on caries: 5 year results. J R Soc Health 105, 99-103.

3. Marino R: (1995) Schould we use milk fluoridation? Bulletin of PAHO, 287-298

4. Stephen KW, Boyle IT, Campbell D, McNee S, Boyle P: (1984) Fiveyear double-blind fluoridated milk study in Scotland. Community Dent Oral Epidemiol 12, 223-229. 
5. Banoczy J, Ritlop B, Solymosi G, Gombik A: (1990) Anticariogenic effect of fluoridated milk and water in rats. Acta Physiol Hung 76, 341-346.

6. Arnold WH, Cerman M, Neuhaus K, Gaengler P: (2003) Volumetric assessment and quantitative element analysis of the effect of fluoridated milk on enamel demineralization. Arch Oral Biol 48, 467-473.

7. Ivancakova R, Hogan MM, Harless JD, Wefel JS: (2003) Effect of fluoridated milk on progression of root surface lesions in vitro under $\mathrm{pH}$ cycling conditions. Caries Res 37, 166-171.

8. Stößer L, Kneist S, Großer W, Künzel W, Banoczy J: (1995) Der kariesprotektive Effekt der Milchfluoridierung im Tierversuch. Dtsch zahnärztl Ztschr 50, 463-470.

9. Toth Z, Gintner Z, Banoczy J, Phillips PC: (1997) The effect of fluoridated milk on human dental enamel in an in vitro demineralization model. Caries Res 31, 212-215.

10. Steinberg D: Studying plaque biofilms on various dental surfaces. In: Edited by An YH, Friedman FJ, Studying plaque biofilms on various dental surfaces. vol. 23. Totowa, N.J.: Humana Press; 2000 353-370.

11. Marsh PD: (1995) The role of microbiology in models of dental caries. Reaction paper. Adv Dent Res 9, 255-269.

12. Carlsson J: (1997) Bacterial metabolism in dental biofilms. Adv Dent Res 11, 75-80.

13. Bowden GH, Li YH: (1997) Nutritional influences on biofilm development. Adv Dent Res 11, 81-99.

14. Bowen WH: (2002) Do we need to be concerned about dental caries in the comming millennium? Crit Rev Oral Biol Med 13, $126-131$.

15. Gao XJ, Fan Y, Kent J, Van Houte J, Margolis HC: (2001) Association of caries activity with the composition of dental plaque fluid. J Dent Res 80, 1834-1839.

16. ten Cate JM: (1999) Current concepts on the theories of the mechanism of action of fluoride. Acta Odont Scand 57, 325-329.

17. McDougall WA: (1977) Effect of milk on enamel demineralization and remineralization in vitro. Caries Res 11, 166-172.
18. Gedalia I, Davidov I, Lewinstein I, Shapira L: (1992) Effect of hard cheese exposure, with and without fluoride prerinse, on the rehardening of softened human enamel. Caries Res 26, 290-292.

19. Herod EL: (1991) The effect of cheese on dental caries: a review of the literature. Aust Dent J 36, 120-125.

20. Kashket S, DePaola DP: (2002) Cheese consumption and the development and progression of dental caries. Nutritition Reviews 60, 97-103.

21. Lewinstein I, Ofek L, Gedalia I: (1993) Enamel rehardening by soft cheeses. Am J Dent 6, 46-48.

22. Jensen ME, Schachtelle CF: (1983) The cariogenic potential of reference foods and snacks at interproximal sites in the human dentition. J Dent Res 62, 889-892.

23. Morrissey RB, Burkholder BD, Tarka SM: (1984) The cariogenic potential of several snack foods. J Am Dent Assoc 109, 589-591.

24. Navia JM, Lopez H: (1983) Rat caries assay of reference foods and sugar containing snacks. J Dent Res 62, 893-898.

25. Pratten J, Bredl R, Wilson M: (2000) An in vitro study of the effect of fluoridated milk on oral biofilms. Appl Environ Microbiol 66, 1720-1723.

26. Vacca Smith AM, Bowen WH: (2000) The effects of milk and kappa-casein on salivary pellicle form on hydroxyapatite discs in situ. Caries Res 34, 88-93.

27. Phillips PC: (1991) Fluoride availability in fluoridated milk systems. Caries Res 25, 237.

28. Kaufmann M, Bartholmes P: (1992) Purification, characterization and inhibition by fluoride of enolase from Strptoccocus mutans DSM 320523. Caries Res 26, 110-116.

29. Arends J, Christoffersen J, Christoffersen MR, Schuthof J: (1983) Influence of fluoride concentration on the progress of demineralization in bovine enamel at $\mathrm{pH}$ 4.5. Caries Res 17, 455-457.

30. Borsboom PC, vd Mei HC, Arends J: (1985) Enamel lesion formation with and without $0.12 \mathrm{ppm} \mathrm{F}$ in solution. Caries Res 19, 396-402.

31. ten Cate JM, Duijsters PP: (1983) Influence of fluoride in solution on tooth demineralization. II. Microradiographic data. Caries Res 17, 513-519. 